\title{
Pursuit of a sustainable tourism policy by connecting historical sites and ancient conventions in Seoul
}

\author{
KyuChull Lee \\ Graduate School, Global Culture \& Contents, \\ Hankuk University of Foreign Studies, Seoul, Republic of Korea \\ JongOh Lee \\ Graduate School, Global Culture \& Contents, \\ Hankuk University of Foreign Studies, Seoul, Republic of Korea
}

\begin{abstract}
Gyeongbokgung Palace is the most visited historical site in Seoul. With Gyeongbokgung Palace in the middle, Jongmyo Shrine is located to the left on Jongno 5-ga and Sajikdan Altar to the right in Sajik-dong. Currently, two events take place here-changing of the guards at Gyeongbokgung Palace and a memorial rite at Jongmyo Shrine-buttheyare conducted separately, whichindicates the lack of focus in explaining the connection between Seoul's historical sites and history. Historical content that can be used to address this includes the procession of the king of Joseon and jikso activities by Joseon's people. Jiksois a way to appeal directly to the king instead of a state agency about the people's problems. The king's ceremonial walk from the palace can be linked to Jongmyo Shrine, Sajikdan Altar, and the Cheonggyecheon Stream,Joseon's busiest areas. Moreover, historical scenes of communication between the king and people can be recreated in spaces between the palace, Jongmyo Shrine, Sajikdan Altar, and Cheonggyecheon. This example will serve the history and sustainability of the city's capital. Therefore, the present study utilized the Smart Seoul Map operated by the Seoul Metropolitan Government to identify the locations of Seoul's important historical sites and analyze their distribution and scopes of influence and, consequently, identify places that can be utilized as new historical content. Determining how to link the king of Joseon's ceremonial walk and jibs to historical places will help develop historical content to connect historical sites and small cities. This will enable the development of large-scale historical content that links the unit areas outside small cities as well as creation of a new type of urban culture while preserving Seoul's historical nature.
\end{abstract}

Keywords: historical content; sustainability; Seoul; Smart Seoul Map; GIS

\section{Background and purpose}

\section{INTRODUCTION}

Seoul is an emblematic city with the largest number of historical and cultural resources in South Korea. Since the 2000s, South Koreans have visited historical and cultural sites more frequently than before, and the overall number of visitors to these sites has increased due to the rapid increase in the number of tourists.

The most popular historicaland cultural sites in Seoul among visitors are Gyeongbokgung Palace and its surrounding areas and the Joseon-era palaces. These sites are located in the heart of downtown Seoul and provide easy access to places such as BukchonHanok Village and Cheonggyecheon Stream. Gyeongbokgung Palace, Changdeokgung Palace, BukchonHanok Village, and Cheonggyecheon Stream are located conveniently to enable easy access to historical sites, dining, shopping, transportation, and lodging in Seoul.Among Seoul's historical and cultural resources, the most visited are Gyeongbokgung Palace and the surrounding areas. 
As Gyeongbokgung Palace is connected to the Gwanghwamun area, it has optimal accessibility. The National Palace Museum of Korea and National Folk Museum are also located in the same area. Because of these reasons, it is natural that many visitors and tourists congregate in this area. Moreover, as the palaces and museums, such as Gyeongbokgung Palace and National Palace Museum of Korea, are located in the same place, visitors can enjoy both indoors and outdoors depending on the weather as well as access the subway directly. Few places in Seoul have direct access to the center of historical sites via the subway. In addition to the historical symbolism, this is another reason why many people visit the Gyeongbokgung Palace area.

Seoul is not alone in attracting a large number of visitors and tourists to certain historical places; this issue is present in every large city with important historical sites. However, the growing number of visitors to the Gyeongbokgung Palace area and the nearby BukchonHanok Village has caused new and serious social problems such as conflict with local residents due toovertourism. Overtourism has become a serious social problem as the increase in visitors has brought about conflict with local residents.

In the case of Seoul, the ease of sightseeing in the Gyeongbokgung Palace area is definitely an element of attraction for visitors. However, attracting a large number of people to a few historical sites makes it difficult to keep the city sustainable. Therefore, measures are needed to disperse the movement of visitors to historical sites. For example, it is necessary to consider linking Jongmyo Shine and Sajikdan Altar, which are located to the left and right of Gyeongbokgung Palace.

To link the historical sites, the present study focuses on the king of Joseon's ceremonial walk and jikso, the people's convention of direct appeal to the king. Currently, all events taking place at Seoul's historical sites are held at their own locations. Therefore, it is necessary to develop historical content that allows the linking of historical sites.

\section{Review of Related Research Results}

The utilization of historical and cultural resources in Seoul has been conducted in various studies mainly in the fields related to urban tourism. In the early 2000s, a study emphasized the necessity of developing urban tourism resources, classifying the historical scenes of Seoul as 'tangible cultural tourism resources' [1]. Since then, in the 2010s, domestic and foreign tourists increased rapidly. As a result, studies began to analyze the travel routes and preferences of tourists who visited historical sites in Seoul. The historical sites that prior studies noted were old palaces (especially Gyeongbokgung Palace) and Bukchon Hanok Village. Looking into the research contents in more detail, a study analyzed the characteristics of walking tourists' movement and stay, based on the GPS of smartphone applications [2]. This study suggested the efficiency of space utilization, analyzing the fact that tourists in Bukchon Hanok Village stayed long even in narrow alleys, aside from resting spaces.

As the number of domestic and foreign tourists visiting Seoul's historical sites has increased, studies analyzing their visit experiences and preferences have emerged. First, a study explained Seoul's tourist attractions that foreign tourists preferred through 'Flickr data' analysis [3], and another proposed a way to raise the level of tourism culture based on the uniqueness and experiences of tourists who visited Bukchon Hanok Village [4]. In addition, studies have been continuously conducted to analyze the correlation between the experience and satisfaction of visitors to historical sites. Specifically, a study assessed the factors that tourists consider important when they evaluate their satisfaction after visiting old palaces [5], and another analyzed that visitors to Gyeongbokgung Palace took interest in and expressed their satisfaction with educational and entertainment factors rather than convenience or 
human services of tourist attractions [6]. There was also a study that analyzed foreign tourists' experiences to visit Gyeongbokgung Palace by utilizing online reviews of Tripadvisor.com [7]. With the increase in tourists visiting Seoul's historical sites, the achievements of studies that can be conducted on the basis of their experience data are being accumulated.

The explosive increase in domestic and foreign tourists visiting Seoul has brought about new problems in Korean society. Because Seoul was not a traditional tourist city, a lot of efforts were made to increase the number of foreign tourists in Korean society. However, as overseas tourists actually have increased considerably, people have encountered new social problems. Naturally, studies have been conducted to solve these problems. For example, a study analyzed negative factors that local residents in tourist attractions felt regarding tourists [8], and another emphasized that it was necessary to develop new tourist routes by linking areas preferred by tourists [9]. Besides these, a study analyzed the characteristics of tourism resources newly developed from Seoul's deteriorated infrastructure [10].

Albeit limited, several studies have emerged to analyze and solve urban sustainability issues. Specifically, a study suggested a plan for maintaining sustainable development by comprehensively linking the environment, economy, and society [11], and a scholar asserted that for the development of a cultural city, not only visitors to tourist attractions but also resident members should solve their own problems, and then the city can maintain and extend the sustainability [12].

However, attempts have not yet been made to solve the problem that domestic and foreign tourists concentrated on specific areas by creating new contents with historical materials. Therefore, this study intends to suggest measures to maintain and improve urban sustainability in a way that prior studies did not notice.

\section{Scope and Method}

This paper analyzes the distribution and influence of historical sites in Seoul through a Geographic/Geographical Information System (GIS). GIS is currently used in various fields of research, and the system utilized with regard to history is called the Historical Geographic Information System (HGIS). Numerous studies related to history, space, and geography have been published in Western countries since the 1990s[13]. And in the early 2000s, studieswerepublished that examinedhistorical issues through GIS [14]. Subsequently, HGISrelated research have continuously produced results [15].

Among the countries in Asia, Japan was the first to conduct relevant research with this method. While HGIS has been actively utilized in Japan since the 1990s, it was after the 2010s that significant research results started to appear[16]. Japan has actively utilized HGIS to produce numerous achievements in restoring not only historical spaces but also social and cultural spaces as well.

In South Korea, interest in HGIS-related research emerged in the 2000s. However, a high quality historical map of South Korea was yet to be produced during the early 2000s; in contrast to China or Japan where such maps were being published duringthe sameperiod. The first South Korean attempt made was to produce an electronic cultural map for the purpose of interpreting the cultural phenomenon of the Joseon Dynasty[17]. Subsequently, a study was proposed to produce a historical map of South Korea using the HGIS method[18]. Specifically, a study on how to produce a historical map of South Korea during the Goryo Dynasty using GIS was presented [19]. Since then, historical studies using GIS in South Korea have increased, for example, suggesting a methodology for identifying regional boundaries in the late Joseon 
Dynasty[20]. Studies in South Korea were not merely a methodology suggestion but were results published by the researchers who produced actual historical maps. Such results indicate that research on producing historical maps using GIS is accelerating in South Korea as well.

The utilization of GIS in the history field in order to grasp the space of a certain era and explain its changes is quite significant. However, the achievements of studies described thus far have beenlimited to the scope of a particular historical period. Therefore, further effort is needed to make an effective use of historical factors and GIS. There has been a lack of research that suggested how to create and utilize new history-related content using GIS/HGIS. For this reason, this paper suggests new historical contents that can be applied to contemporary society by utilizing GIS and historical activities that occurred during South Korea's Joseon Dynasty.

The route taken by Joseon's kings upon leaving Gyeongbokgung Palace or Changdeokgung Palace to visit Jongmyo Shrine or Sajikdan Altar can be confirmed through extant historical records. Since the distance from the palace in Hanyang (Seoul) to Jongmyo Shrine and Sajikdan Altar is not far, the king's procession did not follow a convoluted route. However, as Seoul became modernized and the city center developed, the roads that existed during the Joseon Dynasty have altered greatly. Most bridges once located on the king's route do not exist today. Moreover, it is impossible to restore the scenery from the Joseon Dynasty, as these locations have become bustling streets with a large influx of people.

Therefore, to find a place to utilize the new historical content, this study uses a geographic information system (GIS) to identify historical sites and determine the density of Seoul. The purpose is to identify the city's main historical sites at which people are concentrated and look for empty spaces. This will enable this study to identify a place where historical contents can be used in a novel manner. The hope is to contribute to securing the sustainability in Seoul as well as of other cities by finding ways to link historical places.

\section{CONTENT EXPLAINING SEOUL'S HISTORICITY: 'THE KING’S PROCESSION’ AND 'JIKSO (DIRECT APPEAL)' OF JOSEON}

This section examines the king's procession and the public jikso (direct appeal) that occurred during the Joseon Dynasty in Korea. In Joseon, a pre-modern monarchy, there were limited opportunities for the people to communicate directly with the king. And so, when the king left the palace to perform a state event or a ritual, the people took this opportunity to communicate their problemsdirectly to the king. Accordingly, the king's procession and jiksoarean important context in understanding how communication occurred between the highest authority and the general public during the monarchy of the Joseon Dynasty. Therefore, the following examines of the history and meaning of the king's procession and jikso during the Joseon Dynasty.

Seoul, as the capital of South Korea, has abundant historical and cultural resources compared with other cities, and many of them are linked to the Joseon Dynasty. Simply introducing individual historical sites could sufficiently explain the city's history. However, Seoul currently tends to focus on individual historical sites, such as palaces, Jongmyo Shrine, and Sajikdan Altar. Therefore, a new procedure is needed to explain and sustain the history of Seoul in a more multi-faceted manner.

Seoul is home toGyeongbokgung Palace, a historical monument representing Korea's Joseon Dynasty.To its left is Jongmyo Shrine in Jongno 5-ga, and to its right is Sajikdan Altar in Sajikdong; both of these were built relatively close to the palace because the king visited them 
frequently. Currently, two ceremonies-changing of the guards at Gyeongbokgung Palace and the memorial rite at Jongmyo Shrine-take place here, but each event is conducted separately at its respective location. This shows that there is lack of focus in describing the connection between Gyeongbokgung Palace, Jongmyo Shrine, and Sajikdan Altar.

Historical content that can be used to address this issue include the procession of the king of Joseon and jikso (direct appeal) activities by the people of Joseon. Jiksois a way to appeal directly to the king, the highest leader, instead of a state agency, about the problems suffered by the people. It was very difficult for the people of the early modern era to meet the king or other high officials in person. The people's jikso was mainly conducted during the king's procession outside the palace. This was an act of communication between the people and the highest power, as well as a means for the kingdom to embrace the people. It may be possible to describe Seoul's historical and cultural sites in a more colorful manner if we take advantage of the king's procession and jibs.

The act of jikso was not invented in the Joseon Dynasty. The history of East Asian countries indicates that jibs activities were conducted since ancient times for maintaining the royal system. Historically, every country has had a litigation system. When the people found that general lawsuits did not solve their problems or that there was a problem with the judicial process, they wanted to appeal to the monarch or the chief executive. Jikso was invented with this background for the people to make appeals [21].

In sum, jikso can be described as the people's act of appealing directly to the king to solve their problems. There were various ways to carry out jikso. In Joseon, people beat a drum to tell the king about their problems or caused a disturbance outside the palace to attract his attention. However, these methods had many limitations, and the people were unable to meet the king in person. It was not easy for the complainant's opinion to be conveyed directly to the king because it came from outside the palace.

The most popular method used by the people of Joseon for jikso was to appeal directly in front of the royal carriage during the king's procession. When the king was out of the palace, they caused a disturbance or went up to the king to complain about their problems. Not all the details related to the people's jikso before the royal carriage remain in the historical documents from Joseon. However, there are records that enable us to picture the situation at that time. It is possible to see the records related to jikso and the king's reaction to it from the beginning of the Joseon Dynasty.

Records from the time of King Sejo(r. 1455 - 1468)of Joseon show that the number of people who appeared before him and appealed reached thousands [22]. The actual number of people who came to the king's palanquin and complained about their problems may not have reached this number, and it is possible that this has been exaggerated in part given the nature of historical records. However, one can imagine that there were many cases of people, having waited for the king's procession, complained to him about their problems.

Joseon's King Sejo again pointed out to his officials in the following year that there were many attempts by the people to appeal directly to him, but they could not reach him. At the same time, he ordered that the appeals be conveyed to him in all cases related to life and death [23]. These records show that the people at the time tried to state their problems directly to the king. Moreover, King Sejo is regarded as one of the absolute monarchs of the Joseon Dynasty. The fact that the people wanted to appeal directly to King Sejo, who had strong political power, confirms that members of the Joseon Dynasty tried to convey their problems to the king. 
The atmosphere in Joseon during the reign of King Seongjong(r. 1469 - 1494)can also be identified. King Seongjong feared that not all complaintswere communicated to him, as many people were doing jikso. Therefore, he appointed temporary officials to determine the full details of the jikso [24]. At the time, King Seongjong pointed out that it was a problem when hundreds of people blocked the procession and complained about their mistreatments. His view was that theirs were minor problems; nevertheless, many people were trying to appeal to the king directly. Even under such circumstances, King Seongjong said he would not prohibit the act of jikso, but he would punish the individuals if they complained about minor issues[25].

Jikso continued during the mid- and late-Joseon Dynasty. During King Jungjongs reign(r. 1506 1544), there were many cases of people waiting for the king's procession to make a jikso about problems they had already complained about. Therefore, he made a rule to punish people who made the same jikso twice within the duration of a month [26]. Nonetheless, jikso continued to be important. The kings of the mid- and late-Joseon Dynasty tried to constantly identify what the people were complaining about [27]. There were cases wherein the king's procession or schedule was much delayed due to too many appeals, but the act of jikso itself was never prohibited [28].

In sum, during the Joseon Dynasty, jikso was closely related to the king's procession. The people of Joseon waited for the procession that started from the palace. The king's procession was an important spectacle in the Joseon Dynasty and an opportunity to appeal one's problems directly to the king.

The king's procession, which starts from the palace, can be linked to Jongmyo Shrine and Sajikdan Altar, or Cheonggyecheon Stream, which was the busiest area of Joseon. In addition, historical scenes of the king and his interaction with the people can be restaged in the spaces between the palace, Jongmyo Shrine, Sajikdan Altar, and Cheonggyecheon Stream. This will create an example that embodies the history and sustainability of the city.

Developing historical content that links the royal procession and people's jiksowith the historical palace, Jongmyo Shrine, Sajikdan Altar, and Cheonggyecheon Stream will help create a connection between historical sites and between small cities. If this work is feasible, it will be possible to go beyond small cities and develop large-scale historical content that links unit areas. At the same time, we will be able to create a new type of urban culture while preserving the historical nature of the metropolitan city of Seoul.

The king's procession during the Joseon Dynasty consisted, depending on the scale, of either the daega (king's cart or wagon),beige (medium-sized carts), or soga (small carts) [29]. In the case of daega, thousands of people were mobilized. Realistically, it is not easy to stage a daega during the king's procession. It will be difficult to conduct reenactments that exceed a certain scale in Seoul. Therefore, we should organize the royal procession based on the soga.

It is necessary to utilize the space between Gyeongbokgung Palace, Jongmyo Shrine, and Sajikdan Altar, or the area around Gwangtonggyo Bridge in Cheonggyecheon Stream. In Seoul, there is a limitation in reproducing the actual king's procession and the people's jikso. Therefore, it is necessary to plan the king's procession from the palace as a historical event that takes place on a particular day. However, if the jikso event takes place around Cheonggyecheon Stream, it will be possible to set a specific time. 
THE LOCATION AND OVERTOURISM ISSUES OF IMPORTANT HISTORICAL SITES IN SEOUL

This section describes the issues surrounding location and overtourism at important historical sites in Seoul, the capital of South Korea. Since 2010, the number of overseas and domestic tourists visiting Seoul has increased rapidly.Seoul contains important historical sites such as palaces and Jongmyo Shrine that represent the Joseon Dynasty. Major historical sites such as palaces, Jongmyo Shrine, Bukchon Village, and Cheonggyecheon are concentrated in Jung-gu and Jongno-gu in Seoul. Accordingly, tourists visiting Seoul are concentrated in this area as well. This concentration of tourists creates a new problem called overtourism.

Seoul has served as the capital since the Joseon Dynasty. In the early days of this dynasty, the capital was relocated from Gaegyeong (currently Kaesong in North Korea) to Hansungbu (or Hanyang and currently Seoul). Since then, Hanyang has been the most important city of the country. Naturally, important historical sites, including palaces, Jongmyo Shrine, and Sajikdan Altar, were built within Seoul during the Joseon Dynasty. Table 1 presents a list of important historical sites in Seoul and their addresses. 
Table 1. Locations and administrative districts of important historical sites in Seoul

\begin{tabular}{|c|c|c|c|c|}
\hline No. & Name & Address & District & Period \\
\hline 1 & Gyeongbokgung Palace & $\begin{array}{l}\text { 1-1(Gyeongbokgung Palace), } \\
\text { Sejong-ro, Jongno-gu, Seoul }\end{array}$ & Jongno-gu & Joseon \\
\hline 2 & Gwanghwamun Gate & 161, Sajik-ro, Jongno-gu, Seoul & Jongno-gu & Joseon \\
\hline 3 & $\begin{array}{l}\text { Deoksugung } \\
\text { Palace(Daehanmum Gate) }\end{array}$ & 99, Sejong-daero, Jung-gu, Seoul & Jung-gu & Joseon \\
\hline 4 & Sungnyemun Gate & 40, Sejong-daero, Jung-gu, Seoul & Jung-gu & Joseon \\
\hline 5 & $\begin{array}{l}\text { Changdeokgung } \\
\text { Palace(Donhwamun Gate) }\end{array}$ & 99, Yulgok-ro, Jongno-gu, Seoul & Jongno-gu & Joseon \\
\hline 6 & $\begin{array}{l}\text { Changgyeonggung } \\
\text { Palace(Honghwamun } \\
\text { Gate) }\end{array}$ & $\begin{array}{l}\text { 185, Changgyeonggung-ro, } \\
\text { Jongno-gu, Seoul }\end{array}$ & Jongno-gu & Joseon \\
\hline 7 & Heunginjimun Gate & 288, Jong-ro, Jongno-gu, Seoul & Jongno-gu & Joseon \\
\hline 8 & Dongnimmun Gate & $\begin{array}{l}\text { 941, Hyeonjeo-dong, } \\
\text { Seodaemun-gu, Seoul }\end{array}$ & $\begin{array}{l}\text { Seodaemun- } \\
\text { gu }\end{array}$ & Modern \\
\hline 9 & $\begin{array}{l}\text { Gyeonghuigung } \\
\text { Palace(Heunghwamun } \\
\text { Gate) }\end{array}$ & $\begin{array}{l}\text { 55, Saemunan-ro, Jongno-gu, } \\
\text { Seoul }\end{array}$ & Jongno-gu & Joseon \\
\hline 10 & Jongmyo Shrine & 157, Jong-ro, Jongno-gu, Seoul & Jongno-gu & Joseon \\
\hline 11 & Unhyeongung Palace & $\begin{array}{l}\text { 464, Samil-daero, Jongno-gu, } \\
\text { Seoul }\end{array}$ & Jongno-gu & Joseon \\
\hline 12 & Sajikdan & 89, Sajik-ro, Jongno-gu, Seoul & Jongno-gu & Joseon \\
\hline 13 & $\begin{array}{l}\text { Cheonggyecheon } \\
\text { Stream(Gwangtonggyo } \\
\text { Bridge) }\end{array}$ & Seorin-dong, Jongno-gu, Seoul & Jongno-gu & Joseon \\
\hline 14 & BukchonHanok Village & $\begin{array}{l}\text { 49, Bukchon-ro 11-gil, Jongno- } \\
\text { gu, Seoul }\end{array}$ & Jongno-gu & Joseon \\
\hline 15 & Yeonsangunmyo Tomb & $\begin{array}{l}\text { Mountain 77, Banghak-dong, } \\
\text { Dobong-gu, Seoul }\end{array}$ & Dobong-gu & Joseon \\
\hline 16 & $\begin{array}{l}\text { Amsa-dong Prehistoric } \\
\text { Settlement Site }\end{array}$ & $\begin{array}{l}\text { 875, Olympic-ro, Gangdong-gu, } \\
\text { Seoul }\end{array}$ & Gangdong-gu & Ancient \\
\hline 17 & Jeongneung Royal Tomb & $\begin{array}{l}\text { 116, Arirang-ro 19-gil, } \\
\text { Seongbuk-gu, Seoul }\end{array}$ & Seongbuk-gu & Joseon \\
\hline 18 & $\begin{array}{l}\text { Mongchontoseong } \\
\text { Fortress }\end{array}$ & $\begin{array}{l}\text { 424, Olympic-ro, Songpa-gu, } \\
\text { Seoul }\end{array}$ & Songpa-gu & Ancient \\
\hline 19 & YangcheonHyanggyo & $\begin{array}{l}\text { 53, Yangcheon-ro 47na-gil, } \\
\text { Gangseo-gu, Seoul }\end{array}$ & Gangseo-gu & Joseon \\
\hline 20 & Gyeonggyojang & $\begin{array}{l}\text { 29, Saemunan-ro, Jongno-gu, } \\
\text { Seoul }\end{array}$ & Jongno-gu & $\begin{array}{l}\text { Modern- } \\
\text { contemporary }\end{array}$ \\
\hline 21 & Seonggyungwan & $\begin{array}{l}\text { 31, Seonggyungwan-ro, Jongno- } \\
\text { gu, Seoul }\end{array}$ & Jongno-gu & Joseon \\
\hline 22 & Pungnaptoseong Fortress & $\begin{array}{l}\text { 73-1, Pungnap-dong, Songpa- } \\
\text { gu, Seoul }\end{array}$ & Songpa-gu & Ancient \\
\hline 23 & Samjeondo Monument & 148, Jamsil-ro, Songpa-gu, Seoul & Songpa-gu & Joseon \\
\hline 24 & $\begin{array}{l}\text { Seokchondong Ancient } \\
\text { Tombs }\end{array}$ & $\begin{array}{l}\text { 21, Garak-ro 7-gil, Songpa-gu, } \\
\text { Seoul }\end{array}$ & Songpa-gu & Ancient \\
\hline 25 & Wongudan & 112, Sogong-ro, Jung-gu, Seoul & Jung-gu & Joseon \\
\hline 26 & Jogyesa Temple & $\begin{array}{l}\text { 55, Ujeongguk-ro, Jongno-gu, } \\
\text { Seoul }\end{array}$ & Jongno-gu & $\begin{array}{l}\text { Modern- } \\
\text { contemporary }\end{array}$ \\
\hline 27 & Ujeongchongguk & $\begin{array}{l}\text { 59, Ujeongguk-ro, Jongno-gu, } \\
\text { Seoul }\end{array}$ & Jongno-gu & Joseon \\
\hline
\end{tabular}


Table 1 lists 27 important historical sites in Seoul. Except for four historical sites related to ancient Korean history and three modern-contemporary ones, 20 are related to the Joseon Dynasty. Moreover, the majority of Seoul's important historical sites are located in Jongno-gu and Jung-gu. This shows that during the Joseon Dynasty, Hanyang's major siteswere centered around important palaces such as Gyeongbokgung Palace and Changdeokgung Palace. The palace was the central place where the king lived and carried out state affairs. The king had to visit places such as Jongmyo Shrine and Sajikdan Altar frequently, and so naturally they are located near the palace. This also shows that Jongmyo Shrine and Sajikdan Altar were very important during the Joseon Dynasty. Therefore, the analysis should focus on Jongno-gu and Jung-gu if the king's procession during the Joseon Dynasty is to be used as historical content.

The royal procession during the Joseon Dynasty was conducted in various ways. A large number of people usually attended, since the king's subjects and troops were mobilized. Six layers of supporting staff were deployed to the right and left of the king's palanquin when he moved within the city. When moving at night, the king had to first secure a large space because he needed torchlights to his right and left.

According to Joseon's regulations, the width of the road had to be approximately 18 meters when the king moved within the city, and the number of soldiers mobilized during the king's procession within the city reached 1,500 to 6,000 . Thus, the number of soldiers mobilized alone reached several thousands, and the scale would be even larger if his officials were added. This number was maintained from the early to the late Joseon period. In the late Joseon period, a relatively small number of people, ranging from 400 to 500, weremobilized, depending on the king's preference [30]. When the king went outside the city, the number of people mobilized was even greater. About 5,000 troops were mobilized just to visit the royal tombs near the palace. In some cases, the number reached 6,500 troops. For a royal procession to the tombs, the number reached at least 3,000 [31].

During the Joseon Dynasty, the king's procession was often carried out ona one-day schedule. If it was difficult to limit the schedule to only oneday, the king returned to the palace early morning the next day. He could also have, for example, an eight-day schedule when traveling to a distant place or attending other events [32]. Joseon's kings rarely marched outside the capital city. Most king's journeys were to places near the palace, and a day's visit was arranged. It was not customary for the king to be away from the palace or the capital for an extended time.

The king's procession was itself a special national event, and so it received much attention from members of the kingdom. Moreover, ordinary people in the pre-modern era did not often get the chance to see the king. For the public, the king's procession was a valuable opportunity to see and meet the king. The people naturally gathered to watch the king's procession. Officials had to control the situation when there were too many people, but during the reign of King Gojong(r. 1863 - 1907, the royal procession drew as many as 150,000 people. Around this period, temporary shelters were provided for the crowd, and there were even some fatal accidents [33].

In the same way that the king's procession attracted a lot of crowd during the Joseon Dynasty, many tourists gather in major historical sites in modern Seoul. The number of overseas tourists visiting South Korea, which began to increase from1990, has accelerated in the 2000s. And by the 2010s, Seoul experienced an unprecedented increase in the inflow of foreign tourists. The following graph shows the increasing trends regarding overseas tourists visiting Seoul. 
Figure1 South Korea's Tourism Growth in 2005-2016

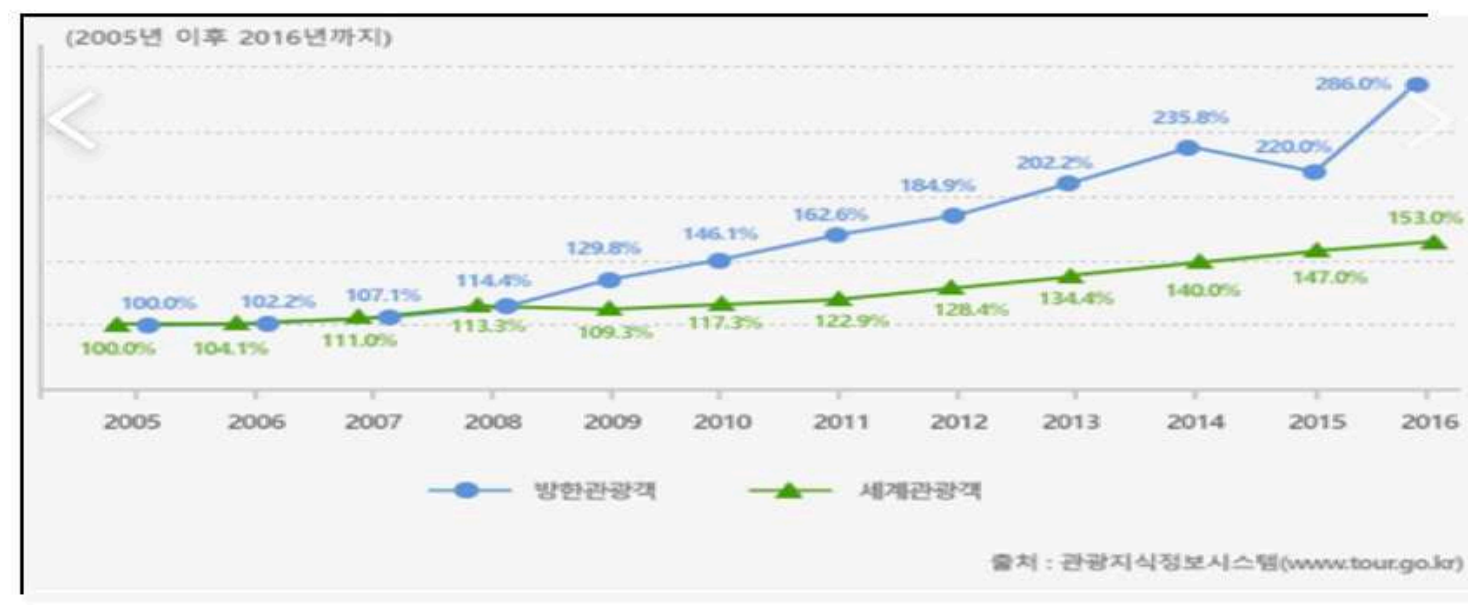

- Foreign Visitors to South Korea $\Delta$ Tourism Around the World

\section{Source : Korea Tourism Organization (www.visitkorea.or.kr), Tourist Knowledge\&Information System (www.tour.go.kr)}

In the figure above, Blue indicates the number of tourists who came to Korea from overseas and Green is the number of tourists around the world. As of 2005 and 2006, the number of tourists around the world has gradually increased. This trend continues, with growth rates exceeding $150 \%$ in 2016. Overall, the number of trips or the number of travelers is increasing. However, it can beseen that the rate of overseas tourists visiting South Korea is much higher. By 2010, the growth rate of overseas tourists visiting South Korea approached approximately $150 \%$. This trend continues to grow even faster, with an increase of approximately $300 \%$ in 2016. As such, the number of overseas visitors to Korea has increased rapidly since 2000.

\section{Figure2 Number of foreign tourists visiting Seoul (unit: 10,000 persons)}

\section{(Source : Tourism Knowledge \& Information System, Korea Culture \& Tourism Institute, Seoul)}

The graph of Figure 2 shows the number of foreign tourists who visited Seoul. In 2010, around seven million foreign tourists visited. However, in 2012 and 2013, more than nine million people visited. The number exceeded 10 million in 2014 and reached 13.5 million in 2016. In less than a decade, from 2010 to 2016, the number of foreign visitors to Seoul has nearly doubled. Looking into this figure with Figure 1 above, we can see how rapidly the number of overseas tourists visiting Korea increased.

Unsurprisingly, one of the mostfavorite places for tourists visiting South Korea is Seoul. Currently, Seoul is experiencing an unprecedented number of overseas tourists, and the rapid increase in tourists has created new social problems. This issue is what has been identified as "Overtourism". Overtourism is a term that entered the lexicon relatively recently. Previously, similar terms existed to highlight the issues caused by the increase and concentration of tourists. Of these, the main two terms used were: "Touristification" and "Tourism-Phobia." Touristification refers to a phenomenon in which locals who reside in a tourist destination move out due to the increase in tourism. And Tourism-Phobia refers to fears or aversions derived from tourism [34].

The notion that the development of tourist sites or tourism activities overburdens local residents and cause new social problems, in addition to merely positive effects, is a topic that has been studied since the 1970s[35]. 
As the number of tourists continues to increase worldwide, overtourism has become a serious social issue for most popular tourist destinations[36]. Typical tourist cities where overtourism has become a serious problem are places such as Venice[37], Italy and Barcelona, Spain. In addition, there are two published studies on the cases of Shenzhen in China [38] and Goa in India [39], respectively. The phenomenon that the rapid increase in tourists creates new social problems can be described as a global problem. And the same issues are being raised in South Korea.

In South Korea, local residents who live in famous tourist destinations, such as in Seoul and Jeju Island, are experiencing substantial inconveniences due to the large inflowof tourists[40].In particular, the BukchonHanok Village in Seoul is located at the center of South Korea's overtourism problem. These places are trying to resolve the problem of overtourism by regulating the available tourist hours and the number of tourists in a particular area. However, it is very difficult to artificially control the flow of population in areas where no specific boundaries are established.Therefore, it is necessary to create an environment in which tourists can move to areas of low density around historical sites.Solving social problems such as overtourism will play an important role in increasing and maintaining the sustainability of a particular city.

\section{Figure3 Places visited by foreign tourists (unit: \%, multiple answers)}

\section{(Source: '2013 International Visitor Survey', Ministry of Culture, Sports and Tourism)}

The graph of Figure 3 displays the places preferred by tourists visiting Seoul from abroad. It can be identified that overseas tourists preferred to visit palaces (39.1\%) except for the two shopping areas. Looking into the graph further, we can see that a large number of overseas tourists paid a visit to historical sites, such as Cheonggyecheon Stream, Namsan Hanok Village, BukchonHanok Village, etc. If the analysis was conducted not by specific places but by regions such as Jung-gu and Jongno-gu of Seoul, it can be presumed that tourists visiting Seoul were concentrated on specific areas. That is, we can find the phenomenon that tourists are concentrated on the regions where shopping places and historical sites are gathered.

For this reason, it is vital to draw a large number of visitors outside the main historical sites while reproducing the some interesting content that exists in Korean history.Today, it is necessary to consider ways to use the king's procession and jikso as historical content. First, the king's procession cannot take place far away from the palace. It would be difficult to reproduce and practically impossible because road conditions have changed much since the Joseon era. It is also difficult to reproduce verbatim the massive royal procession as described in historical documents. This is because we need to consider practical issues such as the mobilization of personnel and budget. Therefore, it is necessary to think of ways to re-enact the king's procession starting from major palaces such as Gyeongbokgung Palace and Changdeokgung Palace to nearby places, such as Jongmyo Shrine, Sajikdan Altar, and Cheonggyecheon Stream. We also need ways to make use of content related to jikso. It will then be necessary to prepare and utilize contents related to the royal procession and jikso centering around Jongno-gu and Jung-gu, where important historical sites of the Joseon Dynasty are located. Since these areas are the most crowded places in Seoul because of visitors and tourists, we have to find places in this area to ensure that people can spread out. If such a route can be found, we can allowthe people to spread out and look at the history of Seoul more conveniently. 


\section{ANALYSIS AND SPACE UTILIZATION OF SEOUL'S DISTRIBUTION OF IMPORTANT HISTORICAL SITES USING THE SMART SEOUL MAP}

In this section, we propose ways to resolve the issue pertaining to the dense concentration of tourists at certain historical sites in Seoul. For this, we first identified the locations of important historical sites in Seoul and analyzed the range of influence associated with these sites using GIS. Through this, we explain the need to utilize the influence range of historical sites that drawsfewer tourists as well as locations with a lower level of tourist density. These low-density locations can be used to provide historical content such as king's procession and jikso.

The Seoul Metropolitan Government operates a GIS program called "Smart Seoul Map (map.seoul.go.kr)" [41].Smart Seoul Map allows the user to mark major historical sites in Seoul and set a range of influence for each area. Through the use of this program, we attempt to identify locations where contentwith regard to the Joseon Dynasty can be reproduced while dispersingtourists.

Research utilizing GIS in order to identify various situations that cannot be verifiedthrough mere historical data has been conducted continuously. For example, the University of Portsmouth in the UK operates the Great Britain GIS [42], and Harvard University visualizes and provides a variety of information on the natural environment and social facilities of the Ming and Qing dynasties through the China Historical GIS [43]. A Japanese case is the Virtual Kyoto project. This project was conducted between 2002 and 2006 at Ritsumeikan University, and provides the spatial information of Kyoto in 3D from the Heian period to the presenttime [44].

Related research is ongoing in South Korea as well.However, due to data limitations, actual research tends to focus on the changes in Seoul during the era of Japanese occupation.Hanyang, the capital of the Joseon Dynasty, underwent a significanttransformation due to changes that occurred from the Korean Empire(r. 1897 - 1910)to Japanese occupation period(r. 1910 1945)[45]. Duringthis process, a residentialdivide was formed around Cheonggyecheon in which theKoreans resided in the north of the stream and the Japanese in the southDuring the Japanese occupation era, Bukchon, a high-class residence of Joseon, lost its status to Namchon, where the Japanese lived[46].

For this reason, studies have been conducted that identified the historical significance caused by the various changes in modern-day Seoul utilizing GIS. For example, a prior study that analyzed the expansion of modern Seoul and changes in land use [47] and a study on the process of change in the northeastern part of modern Seoul [48] were performed using the same methodology.In addition, a study that analyzed the process of commercialization of Seoul in the Joseon Dynasty [49], and also a study that explained the process of the wealthy people living in a certain area during the Japanese colonial period [50] have been conducted as well. Furthermore, there was also a study that examinedareal boundaries during the Japanese colonial period through GIS [51], as well as a comprehensive analysis on road networks and the distribution of buildings in Jeju Island in the 1910s [52].

These studies produced results using GIS/HGIS to examine regional changes and explained their historical significance.However, due to the limitation of data, moststudies focused on the period of Japanese occupation, and the area of analysis was limited to Seoul.It is apparent that the above studies primarily utilized data from the capital city of Seoul; where the largest amount of geographic information remained during the Joseon Dynasty and Japanese occupation. However, this also indicates the lack of active historical research that uses GIS. 
Existing studies have concentrated on the analysis of periods after modern times due to data limitations. In the case of modern times, analyses could be conducted by combining GIS, as there were maps reflecting the scales. On the other hand, in the pre-modern era, including the Joseon Dynasty, there is no map that can allow present researchers to use the same method. However, in Seoul, most of the historical and cultural sites of the Joseon Dynasty currently remain in the same locations. Thus, there is an advantage that can supplement the limitations of antique maps.

In this regard, the 'Cultural Heritage GIS Service' operated by the 'Cultural Heritage Administration' of Korea provides useful information as a GIS service based on the locations of cultural properties [53]. However, the way to directly participate in the program for the analysis and utilization of historical and cultural contents is very limited. Therefore, through the recently developed 'Smart Seoul Map', we will proceed with the utilization of historical and cultural contents [54]. The reason is that this service allows the participants to set up spaces for points, lines and sides and use several analysis tools. This GIS program provides an opportunity for participants to apply their ideas of utilizing historical and cultural contents directly to specific areas. As a user-participated program, the 'Smart Seoul Map' is considered a good tool for the utilization of historical and cultural resources.

Moreover, there has yet to be research that suggests ways to utilize new historical content in modern society other than explaining the change in history through GIS. Therefore, it is necessary to actively seek new locations in order to utilize the historical contents of the Joseon Dynasty such as the king's procession and jikso, as presented above.

Using this, it is possible to mark major historical sites in the city and set the scope of influence of each area on its surroundings. For analysis, the above-mentioned Gyeongbokgung Palace, Jongmyo Shrine, Sajikdan Altar, and Cheonggyecheon Stream are set as "historical content" themes and indicated with red icons. However, since Gyeongbokgung Palace serves as the center of the city's historical and cultural resources, the inside of the palace and front of the Gwanghwamun Gate are marked as separate areas. Historical sites marked with red icons are located inside Jongno-gu, Seoul, and are represented in Figure 4.The scale of the map was set to 1:5000. It can be adjusted directly by the participant, depending upon the situation of the analysis and experiment.

Figure 4. Icon display of the historical content theme (red icons).

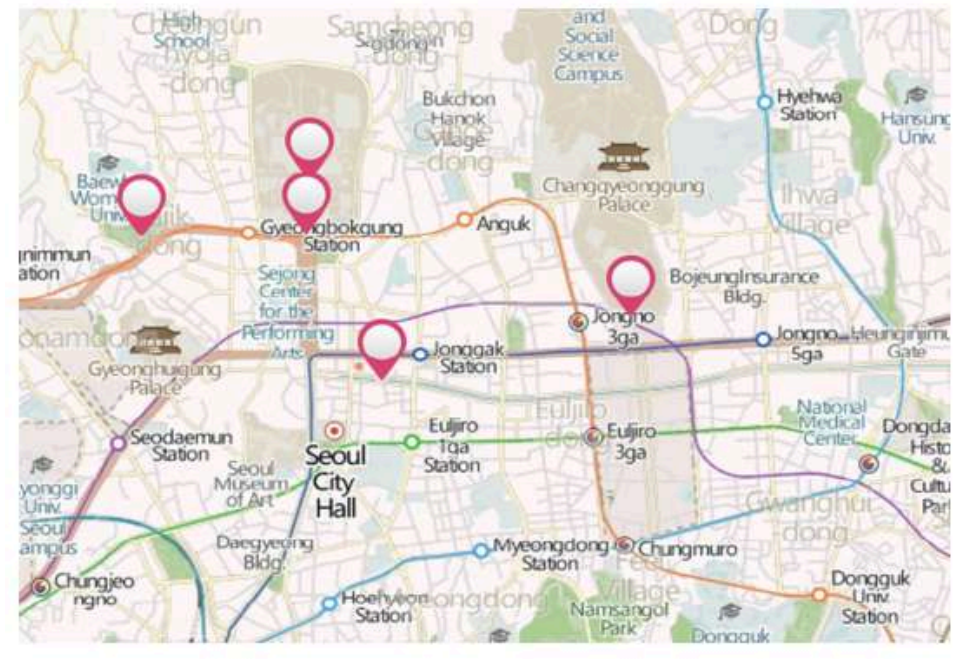

Next, we examine the influence and relevance of historical and cultural sites within the historical content theme and located in the surrounding areas. Therefore,the major historical 
sites around Gyeongbokgung Palace, Jongmyo Shrine, Sajikdan Altar, and Cheonggyecheon Stream are marked with yellow icons. The theme for the places indicated in yellow is "cultural heritage."BukchonHanok Village, Changdeokgung Palace, Deoksugung Palace, Gyeonghuigung Palace, Sungnyemun Gate, Heunginjimun Gate, Independence Gate, and Unhyeongung Palace are markedthis way. All such sites are located in Jongno-gu and Jung-gu, except for the Independence Gate, which is located in Seodaemun-gu. Even if we do include Independence Gate, one can see from the map in Figure 5 that the historical sites are relatively close to each other. This figure indicates the sites marked with yellow icons.

Figure 5. Icon display of the cultural heritage theme (yellow icons).

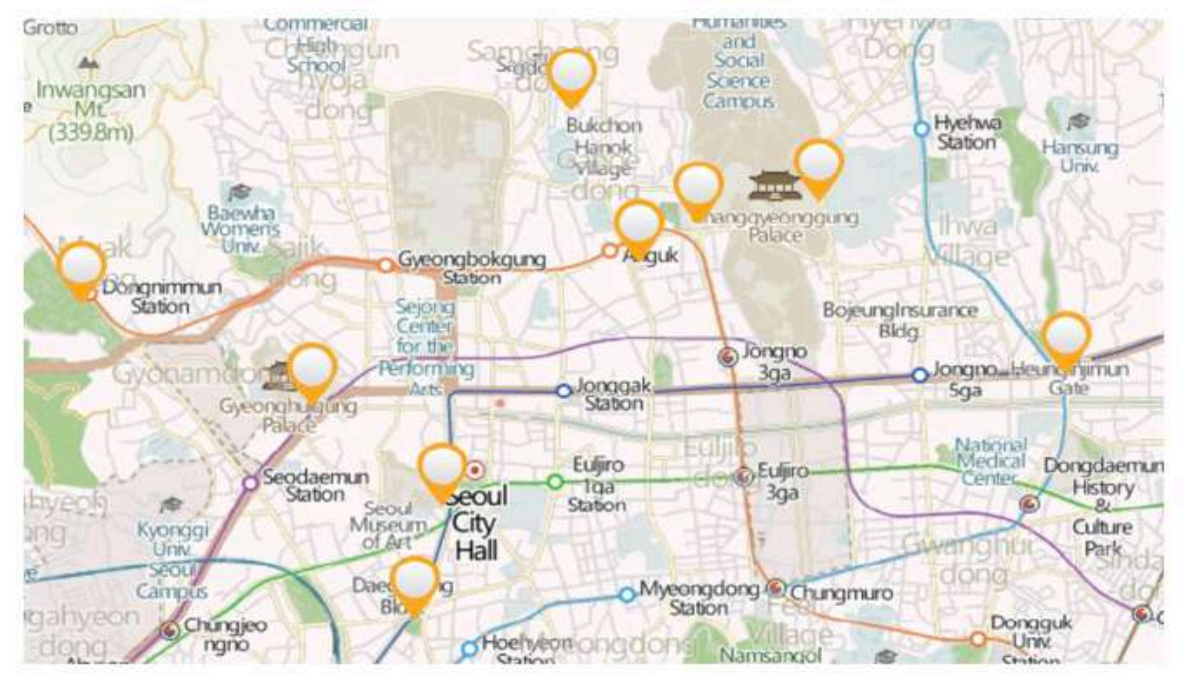

Figure 6includes a map that shows both the red and yellow icons indicated in Figures 4 and 5 . As explained above, the historical sites indicated with red icons and designated as historical content are all located in Jongno-gu. Historical sites indicated with yellow icons are designated as cultural heritage and include Jung-gu and Seodaemun-gu in addition to Jongno-gu, since the historical sites are quite close to each other. The historical sites shown on the map are accessible onfoot, with small differences depending on the route.

Figure 6. Icon display of both historical content and cultural heritage themes (red and yellow icons).

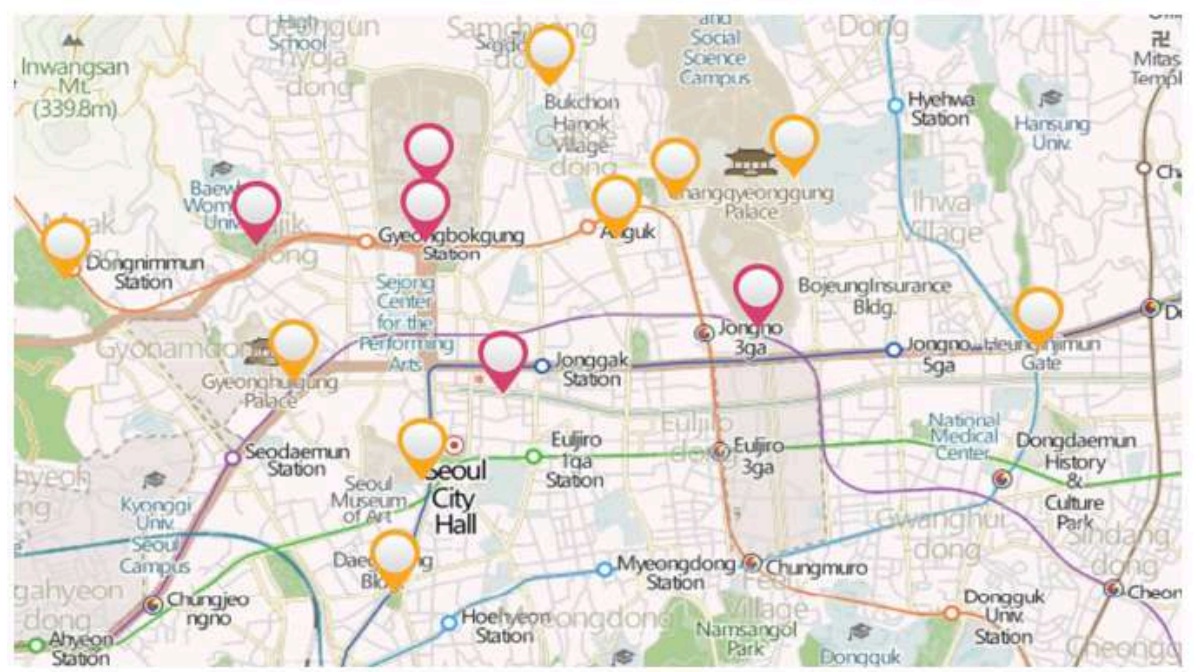

The names of the historical sites in Figure 6 and their addresses are listed in Table 2. As previously explained, historical sites of the Joseon Dynasty are centered around Jongno-gu and 
Jung-gu. In particular, we should pay more attention to the palace and main streets within Seoul if the focus is the royal procession. Gwanghwamun Square, which is in front of Gyeongbokgung Palace, Bukchon Village, and Cheonggyecheon Stream also served as residential areas and were busy streets used by many officials, merchants, and people during the Joseon Dynasty. In fact, these areas attract the most people who want to experience Seoul's historical sites.

Table 2.Indication and locations of the historical sitesin Seoul

\begin{tabular}{|c|c|c|c|}
\hline No. & Name & Address & Icon color \\
\hline 1 & Gyeongbokgung Palace & $\begin{array}{l}\text { 1-1(Gyeongbokgung Palace), Sejong-ro, Jongno- } \\
\text { gu, Seoul }\end{array}$ & Red \\
\hline 2 & Gwanghwamun Gate & 161, Sajik-ro, Jongno-gu, Seoul & Red \\
\hline 3 & $\begin{array}{l}\text { Deoksugung } \\
\text { Palace(Daehanmum Gate) }\end{array}$ & 99, Sejong-daero, Jung-gu, Seoul & Yellow \\
\hline 4 & Sungnyemun Gate & 40, Sejong-daero, Jung-gu, Seoul & Yellow \\
\hline 5 & $\begin{array}{l}\text { Changdeokgung } \\
\text { Palace(Donhwamun Gate) }\end{array}$ & 99, Yulgok-ro, Jongno-gu, Seoul & Yellow \\
\hline 6 & $\begin{array}{l}\text { Changgyeonggung } \\
\text { Palace(Honghwamun Gate) }\end{array}$ & 185, Changgyeonggung-ro, Jongno-gu, Seoul & Yellow \\
\hline 7 & Heunginjimun Gate & 288, Jong-ro, Jongno-gu, Seoul & Yellow \\
\hline 8 & Dongnimmun Gate & 941, Hyeonjeo-dong, Seodaemun-gu, Seoul & Yellow \\
\hline 9 & $\begin{array}{l}\text { Gyeonghuigung } \\
\text { Palace(Heunghwamun Gate) }\end{array}$ & 55, Saemunan-ro, Jongno-gu, Seoul & Yellow \\
\hline 10 & Jongmyo Shrine & 157, Jong-ro, Jongno-gu, Seoul & Red \\
\hline 11 & Unhyeongung Palace & 464, Samil-daero, Jongno-gu, Seoul & Yellow \\
\hline 12 & Sajikdan & 89, Sajik-ro, Jongno-gu, Seoul & Red \\
\hline 13 & $\begin{array}{l}\text { Cheonggyecheon } \\
\text { Stream(Gwangtonggyo Bridge) }\end{array}$ & Seorin-dong, Jongno-gu, Seoul & Red \\
\hline 14 & BukchonHanok Village & 49, Bukchon-ro 11-gil, Jongno-gu, Seoul & Yellow \\
\hline
\end{tabular}

Figures 7 and 8illustrate the results of the distribution analysis based on the locations in Figure 6. First, Figure 7 shows the results when the radius of influence from a certain point was set at 500meters. The analysis results show that the spaces between Gyeongbokgung Palace and Jongmyo Shrine and between Gyeongbokgung Palace and Sajikdan Altar have limited influence. This indicates that it is possible to spread the influence of historical sites that are concentrated around Gyeongbokgung Palace to surrounding areas.

Figure 7. Distribution analysis of the historical and cultural spaces in Seoul.

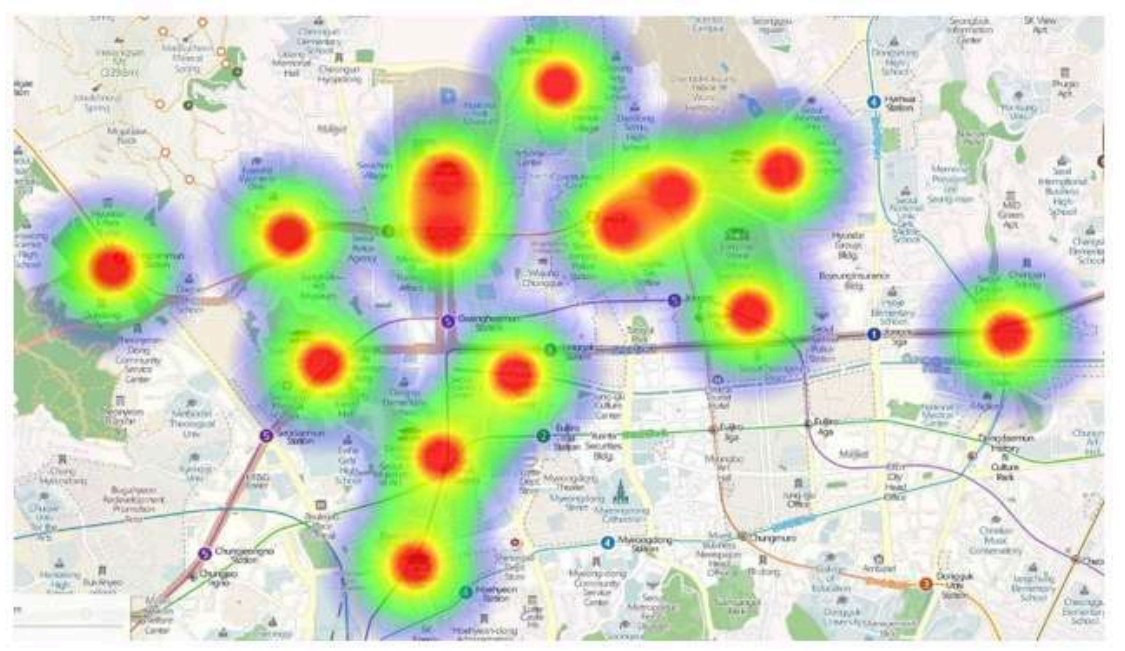


The red areas on the distribution map in Figure 7 indicate the influence of historical sites on surrounding areas and that visitors are concentrated in these areas. They naturally indicate the center of individual historical sites. The red areas are surrounded by yellow and bright green areas. This indicates the extent to which the influence of historical sites is weakened. The outermost purple area indicates places where the influence of historical sites is the weakest. Even when the historical sites' scope of influence is set at a radius of 500 meters, we can see there are empty spaces that individual historical sites do not influence and that have a relatively weak influence. New historical content, such as the royal procession and jibs, should take advantage of spaces where individual historical sites do not have an influence.

However, the scope of influence of individual historical sites indicated in Figure 5 does not yet include all the surrounding transportation or population influx. For a more in-depth analysis, it is necessary to include various information about the area. When the analysis is conducted with various information displayed on the map, spatial analysis using the GIS will be more significant. If this project is carried out, we could suggest ways to utilize historical contents while considering the population density or economic situation of the surrounding areas, along with the scope of influence of historical sites.

Figure 8presents a map of the distribution of historical landmarks on Seoul'sair map to better recognize the above analysis results. This figure shows more clearly the areas over which the historical sites have no influence. It alsoshows that the scope of influence of Joseon's important palaces, such as Gyeongbokgung Palace and Changdeokgung Palace, is quite large. At the same time, of the two royal palaces, the Sajikdan Altar area has less influence than Jongmyo Shrine. This indicates that we need to utilize the new historical content in the space between the palace and Sajikdan Altar instead of that between the palace and Jongmyo Shrine.

\section{Figure 8. Distribution analysis of the historical and cultural spaces in Seoul(air map).}

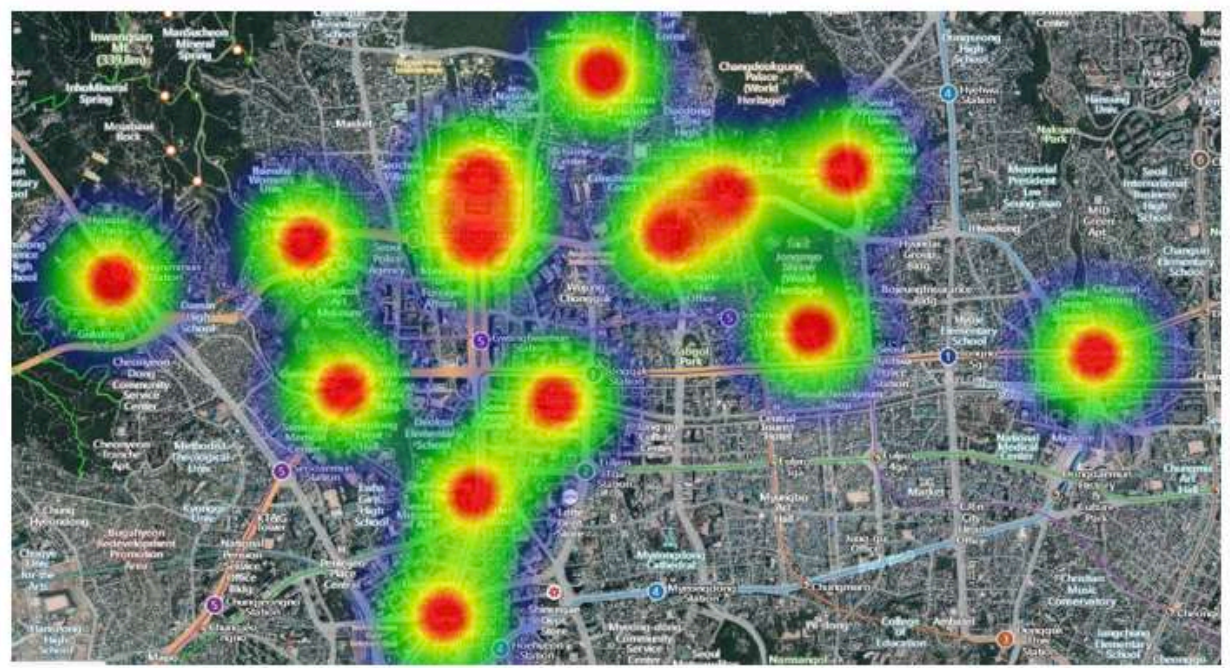

To sum up, through distribution analysis of important historical sites in the city, we found that there is room between Gyeongbokgung Palace and Jongmyo Shrine and betweenGyeongbokgung Palace and Sajikdan Altar to utilize the new historical contents. If historical ceremonies and events such as the royal procession and jibs are used as contents, we can make more efficient use of spaces that are less influenced by historical sites. In addition, it is possible to find a way to utilize the space between different historical sites as well as the surrounding historical sites, with Gyeongbokgung Palace as the center. 
This result will be of great help in finding historical spaces that can be newly utilized. In addition, we will be able to find ways to utilize historical content that is already being used by the public as well as new historical content in a new space. To ensure the sustainability of the historical city of Seoul, it is necessary to reconnect the previously used and not-used historical spaces. If a new method is proposed to utilize and reconnect historical spaces in Seoul, the representative city of Korea, it would provide important criteria for ensuring the sustainability of other cities as well.

\section{CONCLUSION}

This study's analysis showed that Seoul's important historical sites are centered around Jongno-gu and Jung-gu. Since the sites are located relatively close to each other, producing historical content that can link the sites will expand their scopes of influence. Another important fact is that there is a possibility of dispersing the influence of historical sites, which are concentrated around Gyeongbokgung Palace and other adjacent areas, to empty spaces in the surrounding areas. If we can disperse the people, who are concentrated here, to other areas, it will help to not only utilize new historical spaces but also solve the problem of overtourism.

Historical contents that can be used for this purpose are the royal procession of the king of Joseon and jikso. Jikso was carried out in various ways during the Joseon Dynasty. However, the event that people took advantage of most often for jikso was the king's procession. During the king's procession, the people would go before the king's palanquin or cause a disturbance to meet him. This occurred when the king was moving from the palace to another place.

Historical sites representing the Joseon Dynasty are concentrated in Seoul's Jongno-gu and Jung-gu areas. The king's procession during the Joseon Dynasty lasted from one or two days at most. The king visited relatively close places because he could not leave the palace and the capital for long. Jongmyo Shrine and Sajikdan Altar are places the king visited often and are actually located very close to the palace. Therefore, the space between Gyeongbokgung Palace and Changdeokgung Palace to Jongmyo Shrine and Sajikdan Altar needs to be used more appropriately.

The king's procession from the palace can be linked to Jongmyo Shrine and Sajikdan Altar as well as to Bukchon, a high-end residential area of Joseon, and Cheonggyecheon Stream, the busiest area at that time. In addition, it is possible to find ways to recreate the historical scenes in which the king and people communicated in the area between the royal palace and Jongmyo Shrine, Sajikdan Altar, and Cheonggyecheon Stream. This can become an example that satisfies the history and sustainability of Seoul. Thus, using existing and new historical spaces will be significant in helping ensure the sustainability of the City of Seoul.

For this purpose, this study analyzed the scope of influence of historical sites using Smart Seoul Map operated by the Seoul Metropolitan Government. Using this map, we analyzed the locations and distribution of important historical sites in Seoul as well as key historical sites in Jongno-gu and Jung-gu. Having analyzed the area around and spatial influence ofGyeongbokgung Palace and Changdeokgung Palace, the centers of historical space during the Joseon Dynasty, this study concluded that the Sajik-dong area needs to be actively utilized instead of the Jongmyo Shrine area around Jongno 5-ga.In the future, we would like to analyze the population distribution, transportation, and commercial information related to the city's historical space using the GIS. As the scope of analysis of historical spaces becomes wider, we believe that more ways will be proposedto ensure Seoul's sustainability. 


\section{ACKNOWLEDGMENTS}

This work was supported by the Research Fund from Hankuk University of Foreign Studies.

\section{References}

Myung Sook Chun, Min Eui Jung, A Study on Urban Tourism Resources Development in Seoul City, The Academy of Korea Tourism Policy, vol.9 No.1, 2003.

Mi-Hyeon Park, Hee-Jeong Yun, Spatiotemporal Movement Density and Staying Characteristics of Walking Tourists in Bukchon Using GPS-based Smart Phone Application and QGIS, Journal of Tourism Sciences, vol.38, No.9, 2014.

NaYeon Kim, YoungOk Kang, JuYoon Lee, Dong Eun Kim, YeRim Park, Tourists hot spot analysis in Seoul using geotagged photos, Seoul Studies, vol. 20, No. 1, 2019.

Hoo-Suk Lee, Tourists' Authenticity Perception and its Relationship with Tourism Experience: A Sample of Foreign Tourists Visiting Seoul Buckchon Traditional Village, Journal of Tourism Sciences, vol.35, No.2, 2011.

Ji-Sun Kim, Hoon Lee, An Evaluation of the Quality and Level of Satisfaction on Royal Palace Tourism - Focusing on Authentic Experience and HISTOQUAL -, Journal of Tourism Sciences, vol.33, No.6, 2009.

Seol Min Yoon, Jin Ah Park, Choong Ki Lee, Examining the Relationships among Attractive Attribute, Satisfaction, and Loyalty of Ancient Palace as Cultural Tourism Resource : A Case of Visitors to Gyeongbok Palace, Seoul Studies, vol. 13, No. 1, 2012.

Hyun-ju, Lee, Online Review Analysis on Gyeongbokgung :Using data on tripadvisor.com, International Journal of Tourism Management and Sciences, , vol. 32, No. 2, 2017.

Nam-Hee Lee, Nam-Jo Kim, The Effects of Residents' Perceived Crowding on the Emotion and Coping Behavior in Tourism Destination, International Journal of Tourism Management and Sciences, vol. 30, No. 4, 2015.

Beomsoo Han, Hee-Young Kim, Sanghun Park, Strengthening the Placeness by Networks of Cultural Tourism Contents Focused on the Themed Street, Seoul Studies, vol. 9, No. 4, 2008.

Eunhye Choung, A Study on Urban Tourism through Urban Regeneration: Focusing on the Case of Seoullo 7017, Journal of the Korean Urban Geographical Society, vol. 21, No.1, 2018.

Giddings, B., Hopwood, B. and O'Brien, G, Environment, economy and society: Fitting them together into sustainable development, Sustain 10, 2002.

Alvarez-Sousa, A, The problems of tourist sustainability in cultural cities: socio-political perceptions and interests management, Sustainability, vol. 10, No. 2, 2018.

Butlin, R.A., Historical geography: Through the Gates of Space and Time, London: Arnold, 1993.

Knowles, A.K. ed., Past Time, Past Place: GIS for History, California: ESRI Press, 2002.

Ian N. Gregory, Paul S. Ell, Historical GIS - Technologies, Methodologies and Scholarship, Cambridge University Press, 2007.

Myungjin Hong, A Study on the Present Condition and Utilization of the Historical Geography Information System in Japan -Examples of Space Restoration in Japan's Historical Area-, Journal of the Korean Geographical Society 52(6), 2017, pp. 847-849.

Jong-hyuk Kim, The Digitalized Cultural Atlas As a New Research Method for the Humanities in the Era of Digital, Korean Studies 12, 2008.

Jonghyuk Kim, On the Reconstruction of the Historical-Geographical Environment for the Compilation of the Historical Maps, Journal of the Korean Cartographic Association vol. 12, No 2, 2013.

Yo-KeunJeong, Cartography of Goryeo Historical Atlas Based on GIS, The Journa of Korean Medieval History (37), 2013.

Yo-KeunJeong, Restoration of Territories of a County Surrounded by Other Counties in the Late Joseon Period through Use of the GIS Method, The Korean Historical Review 224, 2014.

Hang-seob Bae, Direct Appeal and Political Culture of 'Early Modern' East Asia, Critical Review of History(no, 124), Aut, 2018, pp. 153--154.

Sejo-Sillok, vol. 32, Sejo 10th, Lunar calendar of March 24th, first record.

Sejo-Sillok, vol. 37, Sejo 11th, Lunar calendar of October 12th, second record. 
Seongjong-Sillok, vol. 143, Seongjong 13th, Lunar calendar of July 25th, fourth record.

Seongjong-Sillok, vol. 143, Seongjong 13th, Lunar calendar of July 26th, third record.

Jungjong-Sillok, vol. 44, Jungjong 17th, Lunar calendar of April 19th, third record.

Seonjo-Sillok, vol. 14, Seonjo 13th, Lunar calendar of June 1st, first record.

Yungjo-Sillok, vol. 91, Yungjo 34th, Lunar calendar of January 28th, first record.

THE ACADEMY OF KOREAN STUDIES, Living as the King of the Joseon Dynasty, Dolbegae, 2011, pp. 83-89.

Jiyoung Kim, The Royal Processions of the Kings, and the paths that were taken, during the latter half period of Joseon dynasty, The Institute of Seoul Studies(no. 30), 2008, pp. 43-44.

Jiyoung Kim, Ibid., 2008, pp. 44--45.

Hang-seob Bae, Direct Appeal and Political Culture of 'Early Modern' East Asia, Critical Review of History(no, 124), Aut, 2018, p. 157.

Hang-seob Bae, Ibid., 2018, pp. 157-158.

Shinwook Son, Sanghun Park, Nahyun Lee, Exploratory Study of National Policy Measures on overtourism and sustainable tourism industry, Journal of Tourism Management Research Vol 22, No 4, 2018, pp. 334-338.

Doxey, G, A Causation Theory of Visitor-Resident Irritants, Methodology and Research Inferences. The Impact of Tourism, Sixth Annual Conference Proceedings of the Travel Research Association. September 8-11, San Diego, California. San Diego: Travel Research Association, 1975.

Alexis, P, Over-Tourism and Anti-Tourist Sentiment: An Exploratory Analysis and Discussion. Ovidius University Annals. Economic Sciences Series, vol. 17, No. 2, 2017, pp.288-292.

Seraphin, H., Sheeran, P., \& Pilato, M., Over-tourism and the fall of Venice as a destination, Journal of Destination Marketing \& Management, 2018.

Liang, Z. X. and Bao, J. G, Tourism gentrification in Shenzhen, China: causes and socio-spatial consequences, Tourism Geographies, vol. 17, No 3, 2015.

Routledge, $\mathrm{P}$, 'Selling the rain', resisting the sale: Resistant identities and the conflict over tourism in Goa, Social \& Cultural Geography, vol. 2, No 2, 2001.

Seohyeon Lee, Pre-Overtourism Phenomena and Warning : Looking Back on the Lives of Jeju Residents as Reported by Local Media, Korean Journal of Communication \& Information 88, 2018, pp.78-79.

Smart Seoul Map(http://map.seoul.go.kr).

Great Britain GIS(http://www.gbhgis.org).

https://worldmap.harvard.edu/maps/china-history/Kkj.

Yano, K., et al. Creating Virtual Time-Space of Kyoto, E-journal GEO. Vol. 1, 2006, pp.12-21.; Y. Takase etc, VIRTUAL KYOTO: VISUALIZATION OF HISTORICAL CITY WITH 4DGIS, VIRTUAL REALITY AND WEB TECHNOLOGIES, The International Archives of the Photogrammetry, Remote Sensing and Spatial Information Sciences. Vol. XXXVII. Beijing. 2008.

Kie-JooHyong, Colonial Nature of Seoul Modernization under Japanese Rule, The Journal of Applied Geography,vol. 20, 1997, pp.5-8.

Jong-Geun Kim, A critical assessment on the colonial duality of Kyungsung(Keijō), The Journal of Seoul Studies (38), 2010, pp.36-38.

Sun-Hak BAE, Urban Change Analysis using the 1:50,000 Topographical Map which is Produced at 1910's, Journal of the Korean Association of Geographic Information Studies, vol. 10, no. 3, 2007.

Chang-Woo Kang, Seung-Woo Yang, A Study on the process of urban tissue change in northeast Gyungseong during the Japanese colonial era: focused on Hyehwa-dong, Jongno-gu, Seoul, Korea, The Journal of Seoul Studies (57), 2014.

Seul-Ki Yu, Kyung-Min Kim, The commercialization process in the Eastern areas within city wall of Seoul during Joseon Dynasty, The Journal of Seoul studies (67), 2017.

Seul-Ki Yu, Kyung-Min Kim, The process of being a middle-upper class town of Northeastern areas within Seoul city wall during the Japanese colonization period, Seoul and History vol. 97. 2017. 
Jong-geun Kim, The Legal Formation of the Red-Light Districts and their Locational Characteristics during the Early Colonial Times of Korea, Journal of the Association of Korean Geographers, vol. 6, No. 2, 2017.

Sun-Hak Bae, Eui-Han Lee, Sung-Hoon Jung, An Analysis on the Distribution of Road Networks and Buildings in Jeju-Island in the 1910s, Journal of the Association of Korean Photo-Geographers, vol. 22, No. 3, 2012.

http://gis-heritage.go.kr/information/informationGisG.do.

https://map.seoul.go.kr/smgis/webs/main/main.do. 